\title{
Cultivo da cenoura submetida à aplicação de doses de biofertilizante
}

\section{Growing carrot submitted the application of doses of biofertilizer}

\author{
José Lucas Guilherme Santos ${ }^{l}$; Ancélio Ricardo de Oliveira Gondim ${ }^{2}$; Joaquim Vieira Lima Neto ${ }^{l}$; Erivan Alves da Silva ${ }^{l}$
}

Resumo: O modelo de produção agrícola convencional é economicamente viável, no entanto, é responsável por inúmeros impactos negativos ao meio ambiente e aos indivíduos que o compõe. Baseado neste contexto surge a necessidade à adoção de novas tecnologias que permitam uma produção equiparável, de tal forma que conserve os recursos naturais e que diminua os impactos negativos ao meio ambiente. Com isto objetivou-se neste trabalho estudar o cultivo da cenoura sob a aplicação de biofertilizante. $\mathrm{O}$ experimento foi conduzido em casa de vegetação. Os tratamentos resultaram da combinação dos fatores tempo de fermentação do biofertilizante, 10, 20, 30 e 40 dias e quatro concentrações do biofertilizante, 25, 40, 55 e $70 \%$. O delineamento experimental utilizado foi o inteiramente casualizado, no esquema fatorial 4 x 4, com quatro repetições. As características avaliadas foram altura das plantas e número de folhas a cada 10 dias após o desbaste até a colheita, após a colheita foi avaliado número de folhas, altura das plantas, massa seca das folhas e massa fresca e seca da raiz. Para as características avaliadas ao longo do tempo observou-se que o tempo de fermentação do biofertilizante de 26 dias e a concentração do biofertilizante de $47 \%$ promoveu maior crescimento das plantas. Na colheita, observou-se que em média, o tempo de fermentação do biofertilizante de 30 dias e a concentração do biofertilizante de $50 \%$ promoveram maior crescimento e produção das plantas.

Palavras-chave: Adubo líquido; Daucus carota L.; Fermentação; Produtividade

\begin{abstract}
Conventional agricultural production model is economically viable, however, is responsible for numerous negative impacts on the environment and the individuals who compose it. Based on this context there is a need to adopt new technology providing equivalent production in such a way that conserves natural resources and to decrease the negative impacts on the environment. With this objective of this work was to study the cultivation of carrots under the application of biofertilizers. The experiment was conducted in a greenhouse. The treatments resulted from the combination of factors fermentation time of biofertilizers, 10, 20, 30 and 40 days and four bio-fertilizer concentrations, 25, 40, 55 and 70\%. The experimental design was completely randomized in a factorial $4 \times 4$, with four replications. The characteristics were plant height and number of leaves every 10 days after thinning and harvesting, post-harvest was estimated number of leaves, plant height, dry mass of leaves and fresh and dry root. For the characteristics evaluated over time was observed that the biofertilizer fermentation time of 26 days and the concentration of $47 \%$ biofertilizer promoted greater plant growth. At harvest, it was observed that on average the biofertilizer fermentation time of 30 days and the concentration of $50 \%$ biofertilizer promoted enhanced growth and yield of plants.
\end{abstract}

Keywords: Liquid fertilizer; Daucus carota L.; Fermentation; Productivity

\footnotetext{
*Autor para correspondência

Recebido para publicação em 10/08/2016; aprovado em 30/10/2016

${ }^{1}$ Alunos do Curso de Agronomia, Unidade Acadêmica de Ciências Agrárias, CCTA, UFCG, Pombal, PB, e-mail: lucas1guilherme@hotmail.com; erivanjc2011@hotmail.com; joaquindeps2@hotmail.com

${ }^{2}$ Agronomia, Professor Doutor, Unidade Acadêmica de Ciências Agrárias, CCTA, UFCG, Pombal, PB, e-mail: ancelio.gondim@ccta.ufcg.edu.br
} 


\section{INTRODUÇÃO}

A cenoura (Daucus carota L.) é a hortaliça de raiz tuberosa comestível que possui maior valor econômico no Brasil, sendo cultivada em todo território nacional. Por ano, ocupa uma área equivalente a aproximadamente 25 e 30 mil hectares, com uma produção estimada em 900 mil toneladas de raízes. Está entre as 10 hortaliças mais plantadas no país (MATOS et al. 2011). Essa posição no ranking se dá pelo sabor agradável e, principalmente, pelo valor nutritivo, sendo uma das principais fontes de pró-vitamina A (principalmente o beta-caroteno) (TEÓFILO et al., 2009).

A produção orgânica de hortaliças tem mostrado desenvolvimento significante nos últimos anos no Brasil. A demanda por alimentos saudáveis, produzidos em sistemas ecologicamente sustentáveis, tem se tornado cada vez mais realidade no país, do ponto de vista do consumidor e também por causa da dificuldade dos agricultores familiares arcarem com os custos elevados dos sistemas agrícolas convencionais, além dos problemas toxicológicos advindos do mau uso dos agrotóxicos (MARTINS, 2008).

Resíduos orgânicos de origem animal ou vegetal, tais como estercos de animais, compostos orgânicos, húmus de minhoca e biofertilizantes, têm sido utilizados para a fertilização dos solos (SANTOS, 1992). O uso de biofertilizante surge como uma alternativa de fertilidade do solo e proteção para as culturas, proporcionando o aumento de sua produtividade, pois os biofertilizantes, além de serem importantes fontes de macro e micronutrientes, funcionam como defensivos naturais quando regularmente aplicados via foliar.

Os biofertilizantes líquidos podem ser aplicados sobre as folhas das plantas e sobre o solo, tendo a vantagem de serem rapidamente assimilados pelas plantas. A produção de biofertilizantes ou caldas orgânicas é decorrente do processo de fermentação, ou seja, da atividade dos microrganismos na decomposição da matéria orgânica e complexação de nutrientes, o que pode ser obtido com a simples mistura de água e esterco fresco (TIMM et al., 2004).

Biofertilizantes são compostos bioativos, resíduos finais da fermentação de compostos orgânicos, que contêm células vivas ou latentes de microrganismos (bactérias, leveduras, bacilos, 8 algas e fungos filamentosos) e seus metabólitos, além de quelatos organo-minerais (ALVES et al., 2001). É obtido a partir da fermentação, em sistema aberto ou fechado, com presença ou ausência de ar (aeróbico ou anaeróbico), utilizando esterco fresco de ruminante em lactação, por possuir uma alimentação mais balanceada e rica, o que aumenta a qualidade do produto (SANTOS, 1992). O fornecimento de $\mathrm{N}, \mathrm{P}$ e $\mathrm{K}$ pelos biofertilizantes é de fundamental importância para as funções fisiológicas das plantas, especialmente $\mathrm{N}$, que é constituinte de todos os aminoácidos, proteínas, nucleotídeos, entre outros elementos essenciais as plantas (PRADO, FRANCO e PUGA, 2010). Outro fator que pode ser levado em consideração é que a eficiência dos adubos orgânicos é maior no período inicial de aplicação, devido à taxa de mineralização do $\mathrm{N}$ ser maior nos materiais orgânicos (MUELLER et al., 2013).

Objetivou-se neste trabalho avaliar o cultivo da cenoura em função do tempo de fermentação e doses do biofertilizante.

\section{MATERIAL E MÉTODOS}

O experimento foi conduzido em casa de vegetação no campus do CCTA da Universidade Federal de Campina Grande (UFCG), Pombal - PB, latitude: 6 66'12', S, longitude $37^{\circ} 48^{\prime} 7^{\prime}$ ' W e altitude: $184 \mathrm{~m}$. A cidade de Pombal, situa-se no semiárido do nordeste brasileiro, segundo a classificação de Köppen, o município tipo de clima: BSw'h', clima quente e semiárido, caracterizado pela insuficiência das chuvas, com precipitação pluvial media anual de $700 \mathrm{~mm}$ e temperaturas elevadas acarretando forte evaporação, apresentando temperatura média anual de $30,5^{\circ} \mathrm{C}$ e tendo apenas duas estações climáticas bem definidas durante o ano, uma chuvosa e outra seca.

Os tratamentos resultaram da combinação dos fatores tempo de fermentação do biofertilizante, 10, 20, 30 e 40 dias e quatro concentrações do biofertilizante, $25,40,55$ e $70 \%$. O delineamento experimental utilizado foi o inteiramente casualizado, no esquema fatorial 4 x 4, com quatro repetições.

A adubação mineral de plantio foi aplicada cinco dias antes da semeadura da cenoura. A adubação mineral consistiu da aplicação de $36 \mathrm{~g}$ de $\mathrm{P}_{2} \mathrm{O}_{5}$, de $18,0 \mathrm{~g}$ de $\mathrm{K}_{2} \mathrm{O}$ e de $14 \mathrm{~g}$ de $\mathrm{N}$ por vaso, parcelando igualmente na adubação de cobertura, aos 15, 30 e 45 dias após a emergência, de acordo com Raij, et al. (1996).

As parcelas foram constituídas de um vaso com capacidade de $5 \mathrm{dm}^{-3}$. A semeadura da cenoura (cv. Tropical) foi diretamente no vaso. Quando as mudas apresentarem de 2 a 4 folhas definitivas, foi feito o desbaste das plantas deixando apenas duas plantas por vaso.

O biofertilizante foi obtido nas proporções e materiais que estão presentes na tabela 1 . O biofertilizante foi por fermentação aeróbica, em tambores de plástico; após a fermentação o biofertilizante apresentou as seguintes características, conforme tabela 2.

Tabela 1. Biofertilizante natural enriquecido utilizado no experimento para 200 litros.

\begin{tabular}{lc}
\hline \multicolumn{1}{c}{ Composição } & Quantidade \\
\hline Folhas verdes (picadas) & $4 \mathrm{~kg}$ \\
Farelo de milho & $4 \mathrm{~kg}$ \\
Leite & $1,0 \mathrm{~L}$ \\
Caldo de cana & $1,0 \mathrm{~L}$ \\
Cinzas & $5 \mathrm{~kg}$ \\
Esterco de ovino & $11,0 \mathrm{~kg}$ \\
Micronutrientes & $2 \mathrm{~g}$ de Boro e Zinco \\
NPK & $900 \mathrm{~g}$ \\
\hline \hline
\end{tabular}

Tabela 2. Quantidades totais de nutrientes em cada época de fermentação do biofertilizante.

\begin{tabular}{crrrrr}
\hline \hline Fermentação & \multicolumn{5}{c}{ Quantidade do biofertilizante } \\
\cline { 2 - 6 } & $\mathrm{N}$ & $\mathrm{P}$ & $\mathrm{K}$ & $\mathrm{Ca}$ \\
\cline { 2 - 6 } & & & $\mathrm{mg} \mathrm{L}^{-1}$ & $\mathrm{Mg}$ \\
10 DIAS & 68,20 & 3,99 & 2095,68 & 256,24 \\
20 DIAS & 85,31 & 4,35 & 2552,83 & 724,32 & 479,66 \\
30 DIAS & 85,61 & 9,34 & 2455,57 & 1002,08 & 544,82 \\
40 DIAS & 120,04 & 10,12 & 2424,73 & 718,50 \\
500,72 \\
\hline
\end{tabular}


Foi retirada uma alíquota do biofertilizante aos 10, 20, 30 e 40 dias de fermentação, para quantificar os níveis de concentração de nutrientes em diferentes fases de fermentação. Foi feita cinco adubações (de acordo com os tratamentos), aos 22, 37, 52, 67 e 81 dias após a emergência, aplicando $150 \mathrm{~mL}$ do biofertilizante por vaso.

As características avaliadas foram altura das plantas e número de folhas a cada 10 dias após o desbaste até a colheita, após a colheita foi avaliado número de folhas, altura das plantas, massa seca das folhas e massa fresca e seca da raiz.

Os dados serão submetidos à análise de variância. Caso as características avaliadas sejam significativas, será realizada a análise de regressão ajustando os modelos baseados na significância dos coeficientes de regressão, utilizando-se o teste " $F$ ", nos coeficientes de determinação e no fenômeno biológico.

\section{RESULTADOS E DISCUSSÃO}

\section{Características de crescimento ao longo do tempo}

De acordo com a análise de variância, verificou-se que as características de crescimento foram significativas para os tratamentos com época de fermentação $(\mathrm{F})$, concentração $(\mathrm{C})$ e dias após o transplantio (T).

Observou-se na Figura 1, que o número de folhas das plantas de cenoura apresentaram efeito quadrático com valor máximo de 5,6 aos 26 dias de fermentação, em seguida houve um decréscimo (Figura 1). Comportamento semelhante foi observado quando as plantas foram submetidas a diferentes concentrações do biofertilizante, de tal forma que as plantas apresentaram valor máximo de 5,6 com $48 \%$ de concentração do biofertilizante (Figura 2).

Figura 1. Número de folhas e altura das plantas de cenoura em função do tempo de fermentação do biofertilizante
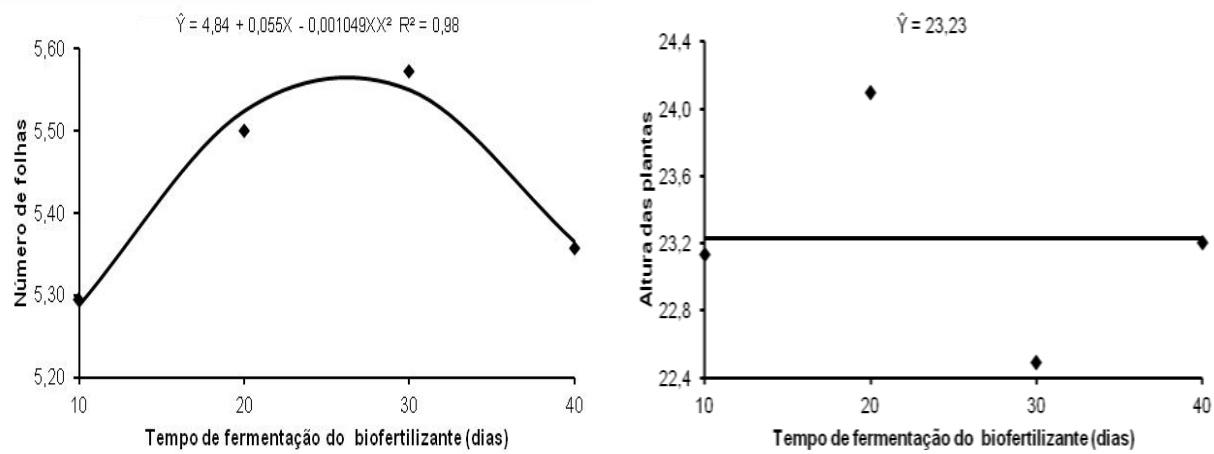

A altura das plantas não foi influenciada pelo tempo de fermentação do biofertilizante, no qual apresentou uma altura média de 23,2 cm (Figura 1). Comportamento diferente foi observado para a altura das plantas quando foram submetidas a diferentes concentrações do biofertilizante, de tal forma que as plantas apresentaram valor máximo de 23,8 com $46 \%$ de

concentração do biofertilizante (Figura 2).

Independentemente do tempo de fermentação e das concentrações do biofertilizante, observou-se que a altura das plantas e o número das folhas aumentaram de acordo com os dias avaliados a cada 10 de dias, respectivamente (Figura 3).

Figura 2. Número de folhas e altura das plantas de cenoura em função da concentração do biofertilizante.

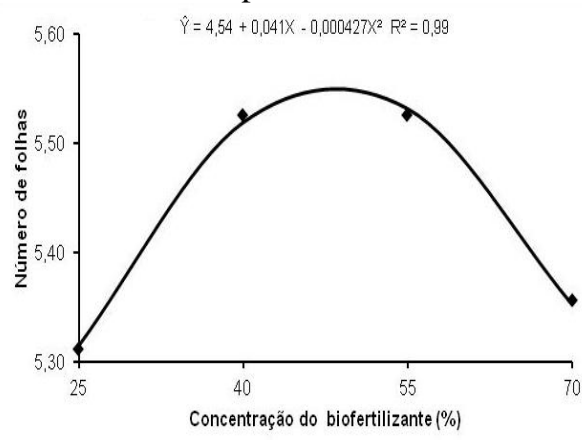

$\left.\hat{Y}=19,513393+0,189583^{*} X-0,002083^{*}\right)^{2} \quad R^{2}=0,54$

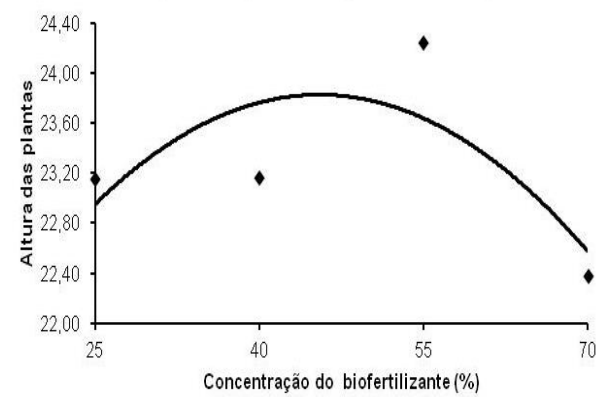

Figura 3. Número de folhas e altura das plantas de cenoura em função dos dias após transplantio.
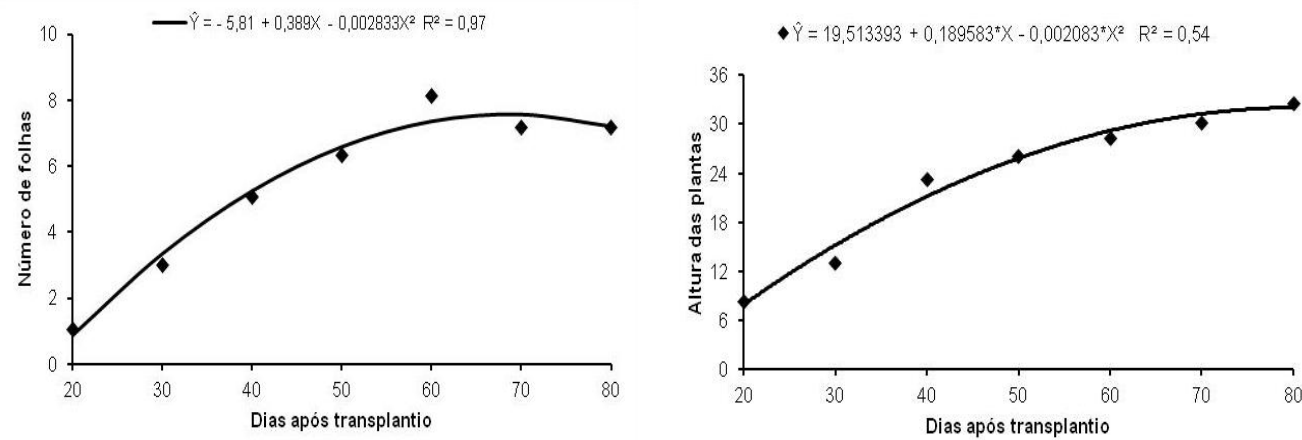


\section{Características de crescimento e produção na colheita}

De acordo com a análise de variância, verificou-se que todas as características avaliadas foram significativas para os tratamentos com época de fermentação $(\mathrm{F})$, concentração $(\mathrm{C})$ e para a interação $\mathrm{F}$ x C, com exceção para o diâmetro da raiz. Como houve interação entre os fatores, isso significa que os fatores não podem ser estudados isoladamente.

$\mathrm{O}$ número de folhas não foi influenciado pela concentração do biofertilizante para os tempos de fermentação de 10 e 20 dias, obtendo valores 7,31 e 7,50, respectivamente. No entanto observou-se que aos 30 e 40 dias de fermentação, o número de folhas apresentou um comportamento linear e quadrático, respectivamente. Para o tempo de fermentação de 30 dias, o número de folhas, aumentou com a concentração do biofertilizante atingindo um valor máximo de 8,0 na concentração do biofertilizante de $70 \%$. Para o tempo de fermentação de 40 dias, o número de folhas inicialmente apresentou um declínio com o aumento da concentração do biofertilizante, este comportamento foi observado até a concentração de $43 \%$ do biofertilizante com 6,7 folhas, em seguida com o aumento da concentração o número de folhas foi aumentando até atingir valores de 7,9 (Figura 4a).

Figura 4. Número de folhas, altura das plantas, massa seca das folhas, massa fresca e seca da raiz de cenoura em função da concentração do biofertilizante e em cada tempo de fermentação.
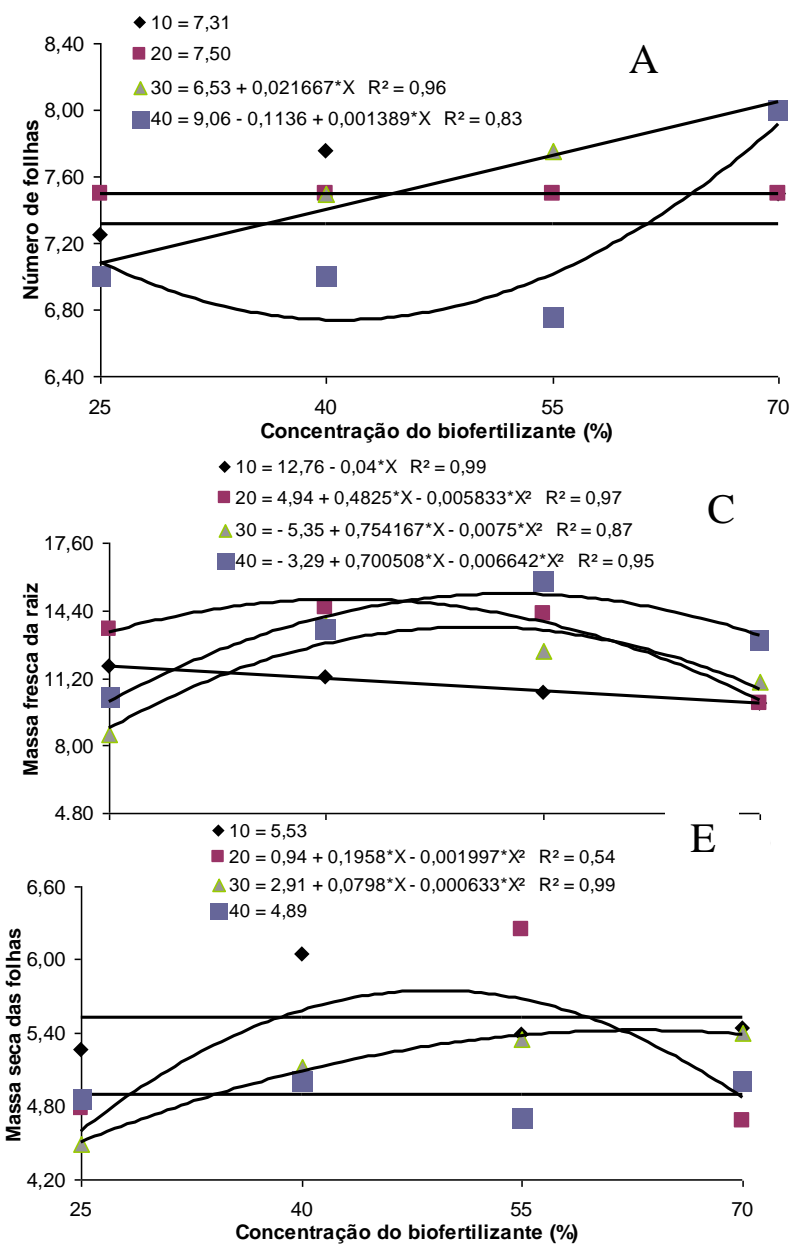

A altura das plantas não foi influenciada pela concentração do biofertilizante para os tempos de fermentação de 10, 30 e 40 dias, obtendo valores 34,4; 33,4 e 35,1 , respectivamente. No entanto observou-se que aos 20 dias de fermentação, a altura das plantas apresentou um comportamento quadrático. Para o tempo de fermentação de 20 dias, a altura das plantas, diminuiu com a concentração do biofertilizante atingindo um valor mínimo de $32,8 \mathrm{~cm}$ na concentração do biofertilizante de $60 \%$. Em seguida com o aumento da concentração a altura das plantas foi aumentando até atingir valores de 33,7 (Figura 4b).

A massa fresca da raiz foi influenciada pela concentração do biofertilizante em todos os tempos de fermentação. Observou-se que aos 10 dias de fermentação, a massa fresca da raiz apresentou um comportamento linear com valor máximo de $12,8 \mathrm{~g}$ para a concentração do biofertilizante de

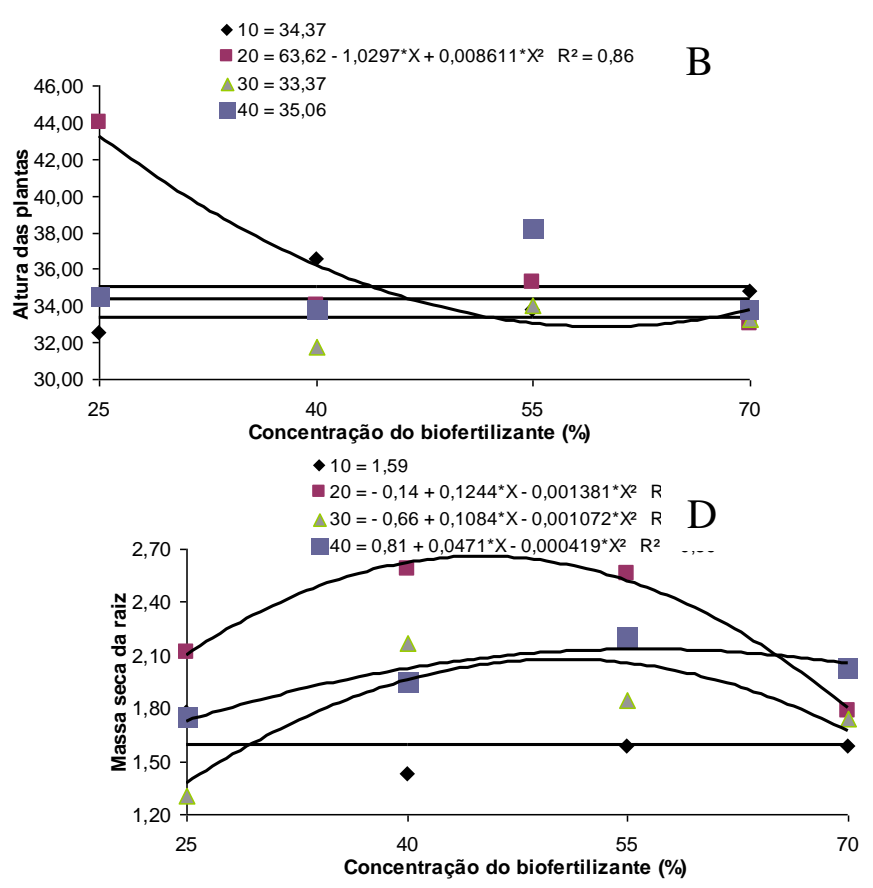

25\%. Para os tempos de fermentação de 20, 30 e 40 dias, a massa fresca da raiz apresentou um comportamento quadrático com valores máximo de 14,9; 13,6 e 15,2 g para as concentrações do biofertilizante de 41; 50 e 53, respectivamente. Em seguida com o aumento da concentração a massa fresca da raiz foi diminuindo (Figura 4c).

A massa seca da raiz foi influenciada pela concentração do biofertilizante em todos os tempos de fermentação com exceção do tempo de 10 dias no qual obteve média igual a 1,59 g. Observou-se que aos 20, 30 e 40 dias de fermentação, a massa fresca da raiz apresentou um comportamento quadrático com valores máximo de 2,66; 2,08 e 2,3 g para as concentrações do biofertilizante de 45; 51 e 56, respectivamente. Em seguida com o aumento da concentração a massa fresca da raiz foi diminuindo (Figura 4d). 
Figura 5. Número de folhas, altura das plantas, massa fresca e seca da raiz, massa seca das folhas, em função do tempo de fermentação e em cada concentração do biofertilizante.

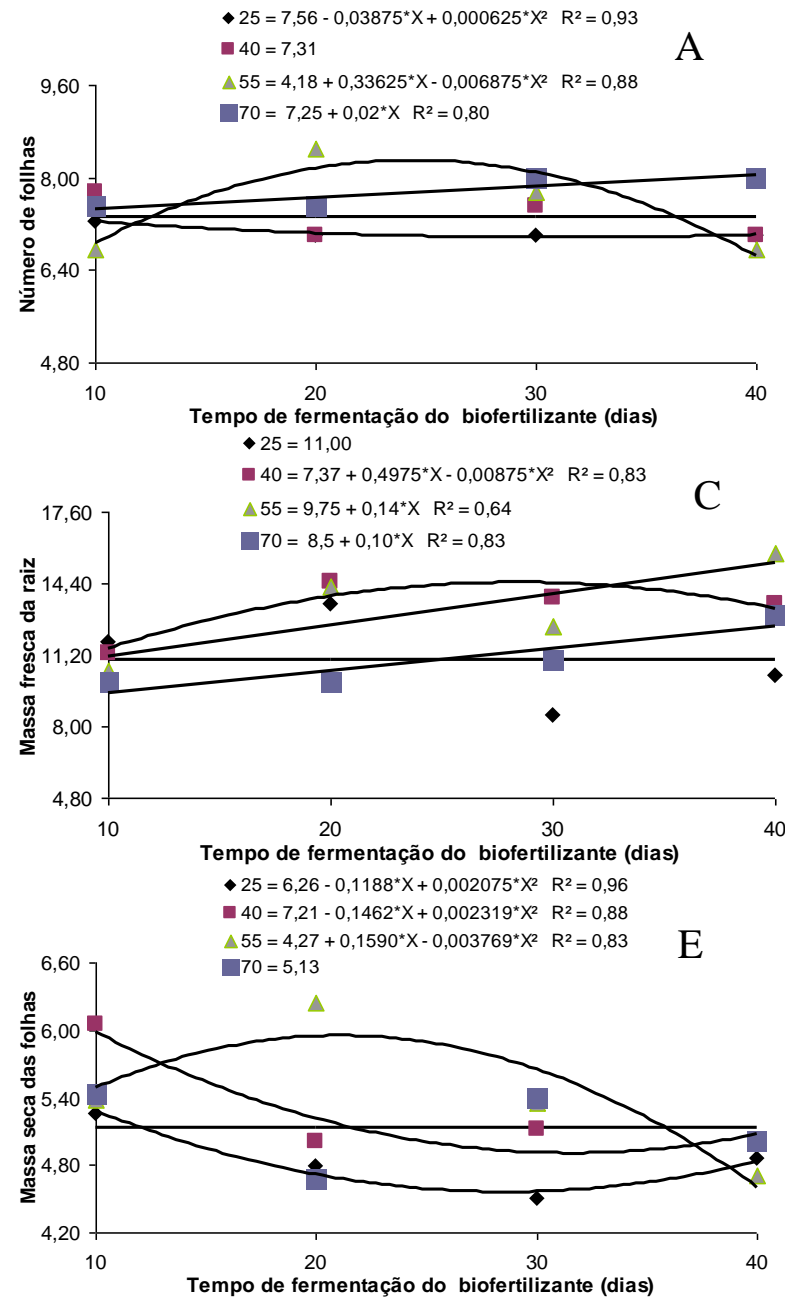

A massa seca das folhas não foi influenciada pela concentração do biofertilizante para os tempos de fermentação de 10 e 40 dias, obtendo valores 5,53 e 4,89, respectivamente. No entanto observou-se que aos 20 e 30 dias de fermentação, a massa seca das folhas apresentou um comportamento quadrático com valores máximo de 5,74 e 5,42 g para as concentrações do biofertilizante de 49 e 63 , respectivamente. Em seguida com o aumento da concentração a massa seca das folhas foi diminuindo (Figura 4e).

$\mathrm{O}$ número de folhas não foi influenciado pelo tempo de fermentação do biofertilizante apenas para a concentração de $40 \%$, obtendo valor de 7,31 . No entanto observou-se que as concentrações de 25,55 e 70\%, o número de folhas apresentou um comportamento quadrático, quadrático e linear, respectivamente. Para a concentração de $25 \%$, o número de folhas, diminuiu com tempo de fermentação do biofertilizante atingindo um valor mínimo de 6,96 folhas no tempo de fermentação do biofertilizante de 31 dias. Para a concentração de 55\%, o número de folhas apresentou um aumento com o tempo de fermentação do biofertilizante, este comportamento foi observado até o tempo de fermentação do biofertilizante de 24 dias com 8,29 folhas, em seguida com o aumento tempo de fermentação do biofertilizante o número de folhas diminuiu. Para a concentração de $70 \%$, o número de folhas, aumentou com tempo de fermentação do biofertilizante atingindo um valor máximo de 8,50 folhas no tempo de fermentação do biofertilizante de 40 dias. (Figura 5a).

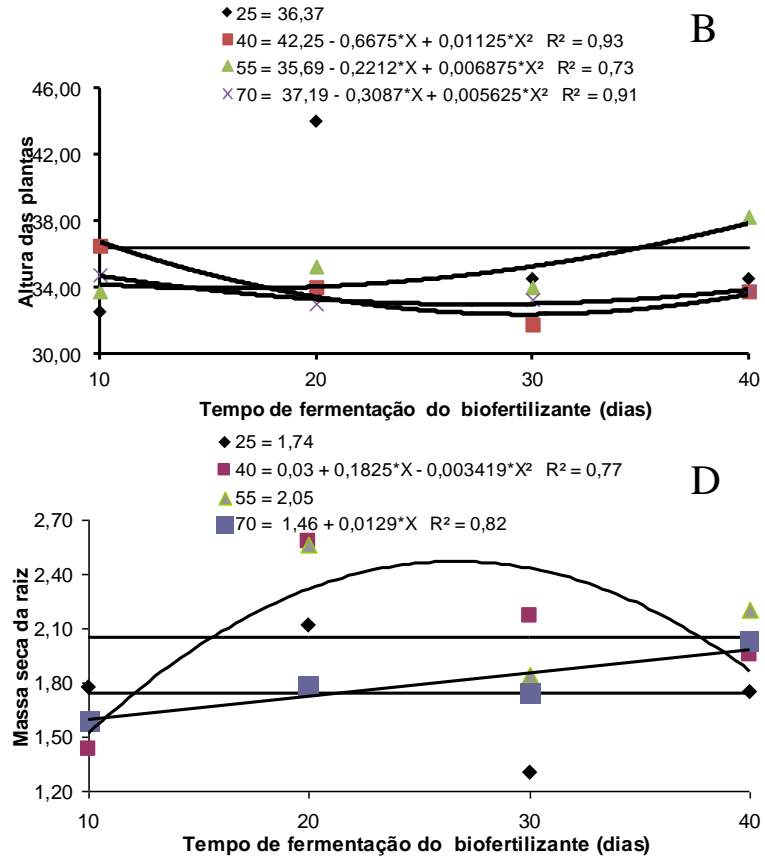

A altura das plantas foi influenciada pelo tempo de fermentação do biofertilizante em todas as concentrações com exceção da concentração de $25 \%$ no qual obteve média igual a $36,37 \mathrm{~cm}$. Observou-se que as concentrações de 40, 55 e $70 \%$, a altura das plantas apresentou um comportamento quadrático com valores mínimos de 32,35; 33,91 e 32,95 cm para os tempos de fermentação do biofertilizante de 30; 16 e 27 dias, respectivamente. Em seguida com o aumento do tempo de fermentação a altura das plantas foi aumentando (Figura 5b).

A massa fresca da raiz foi influenciada pelo tempo de fermentação do biofertilizante em todas as concentrações com exceção da concentração de $25 \%$ no qual obteve média igual a 11,00 g. No entanto observou-se que as concentrações de 40, 55 e 70\%, a massa fresca da raiz apresentou um comportamento quadrático, linear e linear, respectivamente. Para a concentração de $40 \%$, a massa fresca da raiz, aumentou com tempo de fermentação do biofertilizante atingindo um valor máximo de $14,44 \mathrm{~g}$ no tempo de fermentação do biofertilizante de 28 dias. Para a concentração de 55 e $70 \%$, a massa fresca da raiz apresentou um aumento com o tempo de fermentação do biofertilizante, este comportamento foi observado até o tempo de fermentação do biofertilizante de 40 dias com 15,35 e 12,50 g (Figura 5c).

A massa seca da raiz não foi influenciada pelo tempo de fermentação do biofertilizante para as concentrações de 25 e $55 \%$, obtendo valores 1,74 e 2,05 , respectivamente. No entanto observou-se que as concentrações de 40 e $70 \%$ 
apresentaram um comportamento quadrático e linear, respectivamente. Para a concentração de $40 \%$, a massa seca da raiz, aumentou com o tempo de fermentação do biofertilizante atingindo um valor máximo de $2,46 \mathrm{~g}$ no tempo de fermentação do biofertilizante de 28 dias. Para a concentração de $70 \%$, a massa seca da raiz, aumentou com tempo de fermentação do biofertilizante atingindo um valor máximo de 1,98 g no tempo de fermentação do biofertilizante de 40 dias. (Figura 5d).

A massa seca das folhas foi influenciada pelo tempo de fermentação do biofertilizante em todas as concentrações com exceção da concentração de $70 \%$ no qual obteve média igual a 5,13 g. Observou-se que as concentrações de 25, 40 e 55\%, apresentaram um comportamento quadrático com valores de 4,56; 4,91 e 5,95 g para os tempos de fermentação do biofertilizante de 29; 32 e 21 dias, respectivamente. (Figura 5e).

\section{CONCLUSÕES}

O tempo de fermentação do biofertilizante de 26 dias e a concentração do biofertilizante de $47 \%$ promoveu maior crescimento das plantas.

$\mathrm{Na}$ colheita, observou-se que em média, o tempo de fermentação do biofertilizante de 30 dias e a concentração do biofertilizante de $50 \%$ promoveram maior crescimento e produção das plantas.

\section{AGRADECIMENTOS}

O presente trabalho foi realizado com apoio do $\mathrm{CNPq}$, Conselho Nacional de Desenvolvimento Científico e Tecnológico - Brasil pela manutenção da bolsa PIBIC.

\section{REFERÊNCIAS}

ALVES, S. B.; MEDEIROS, M. B.; TAMAI, M. A.; LOPES R. B. Trofobiose e microrganismos na proteção de plantas: biofertilizantes e entomopatógenos na citricultura orgânica. Revista de Biotecnologia, Ciência e Desenvolvimento, Brasília, v. 4, n. 21, p. 16-21, 2001.

ARAÚJO, A. S. F. A qualidade do solo. Sapiência, n.4, p.5, 2004.

ARIAS, C. H. J. Digestión anaeróbica de desechos orgánicos. México: Universidad Autónoma Cha- pingo, 1981. 45p.

D'ANDREA, P. A.; MEDEIROS, M. B. Biofertilizantes biodinâmicos na nutrição e proteção de hortaliças. In: CONGRESSO BRASILEIRO DE AGRICULTURA ORGÂNICA, NATURAL, ECOLÓGICA E BIODINÂMICA, 1, 2002, Piracicaba. Anais... Piracicaba: Agroecológica, 2002.

DIAS, N. S.; BRITO, A. A. F.; SOUSA NETO, O. N.; LIRA R. B.; BRITO, R. F. Produção de alface hidropônica utilizando biofertilizante como solução nutritiva. Revista caatinga, Mossoró, v.22, n.4, p.158-161 162, out.-dez. 2009.

FRIES, M. R.; AITA, C. Aplicação de esterco de bovino e efluentes de biodigestor em um solo podzólico vermelhoamarelo: efeito sobre a produção de matéria seca e absorção de nitrogênio pela cultura do sorgo. Revista do Centro de Ciências Rurais, Santa Maria, v.20, n.1-2, p. 137-145, 1990.

MARTINS, G. de O. Desenvolvimento de raízes de cenoura (Daucus carota L. var Esplanada) em solos submetidos a diferentes compostos orgânicos. Rio Largo, 2008. $43 \mathrm{f}$. Dissertação (Mestrado em Agronomia) Programa de Pósgraduação em Agronomia, Universidade Federal de Alagoas.

MATOS, F. A. C.; LOPES, H. R. D.; DIAS, R. de L.; ALVES, R. T. Agricultura familiar: Cenoura, Brasília: Plano Mídia, 2011.

MEDEIROS D. C.; LIMA B. A. B.; BARBOSA M. R.; ANJOS R. S. B.; BORGES R. D.; CAVALCANTE NETO J. G.; MARQUES L. F. Produção de mudas de alface com biofertilizantes e substratos. Horticultura Brasileira, v.25, n.3, p.433-436, 2007.

MUELLER, S.; WAMSER, A. F.; SUZUKI, A.; BECKER, W. F. Produtividade de tomate sob adubação orgânica e complementação com adubos minerais. Revista Horticultura Brasileira, v. 31, n. 1, p. 86-92, 2013.

PAZ, V. P. S.; TEODORO, R. E. F.; MENDONÇA, F. C. Recursos hídricos, agricultura irrigada e meio ambiente. Revista Brasileira de Engenharia Agrícola e Ambiental , v.4, n.3, p.465-473, 2000.

PRADO, R. M.; FRANCO, C. F.; PUGA, A. P. Deficiências de macronutrientes em plantas de soja cv. BRSMG 68 (Vencedora) cultivada em solução nutritiva. Revista Comunicata Scientiae, v. 1, n. 2, p. 114-119, 2010.

RAIJ, B. V.; CANTARELA, H.; QUAGGIO, J. A; FURLANI, A. M. C. Recomendações de adubação e calagem para o estado de São Paulo. 2.ed. Campinas: Instituto Agronômico e Fundação IAC, 1996. 285p. Boletim Técnico, 100 .

SANTOS, A. C. V. Biofertilizante líquido: o defensivo agrícola da natureza. Niterói: EMATERRIO, 1992.

TEÓFILO, T. M. S.; FREITAS, F. C. L. de; NEGREIROS, M. Z. de; LOPES, W. de A. R.; VIEIRA, S. S. V. S. Crescimento de cultivares de cenoura nas condições de Mossoró-RN. Revista Caatinga, v. 22, n. 1, p. 168-174, 2009.

TIMM, P. J.; GOMES, J. C. C.; MORSELLI, T. B. Insumos para agroecologia: Pesquisa em vermicompostagem e produção de biofertilizantes líquidos. Revista Ciência \& Ambiente, n.29, 2004.

ZAGO, V. C. P.; EVANGELISTA, M. R.; ALMEIDA, D. L.; GUERRA, J. G. M.; PRATA, M. C. P.; RUMJANEK, N. G. Aplicação de esterco bovino e uréia na couve e seus reflexos nos teores de nitrato e na qualidade. Horticultura Brasileira, v.17, n.3, p.207-210, 1999. 